\section{LA VICTIMOLOGÍA A LA LUZ DE LOS DERECHOS HUMANOS ${ }^{\star}$}

\author{
Juan Carlos Abreu y Abreu* \\ Universidad de La Salle, México
}

Fecha de recepción: 3 de diciembre de 2008

Fecha de aceptación: 15 de abril de 2009

Homo sum: humani nil a me alienum puto Terencio. Heautontimorumenos, I,1,25.

Las relaciones humanas no son tan complicadas como las pintan: a menudo son irresolubles, pero no complicadas. Michel Houellebecq. Plataforma.

\section{Resumen}

Si el derecho pretende mantener su legitimidad y no ser absorbido o neutralizado por economistas, políticos o científicos, debe ser una fuente permanente de invocación y de reclamo por la justicia y lo justo, no para proponer soluciones inviables sino para defenderles incansable, inexcusable y eficazmente; lo contrario, significa sacrificar el sentido último legitimador del derecho. La historia ilustra e instruye sobre derechos sin rostro humano o contrarios al hombre, pero también que es posible construir algún derecho que lo favorezca; la opción, es un humanismo jurídico que nos reivindique, que destierre el miedo de sentirnos víctimas.

Palabras clave

Victimología, derechos humanos, humanismo

\section{VICTIMOLOGY IN LIGHT OF HUMAN RIGHTS}

\section{Abstract}

If the law seeks to maintain its legitimacy and not be absorbed or neutralized by economists,

El presente artículo corresponde a la investigación sobre victimología adela0ntada por el autor en la Universidad de La Salle, México.

* Catedrático de la Universidad La Salle y Miembro de la Academia Mexicana de Jurisprudencia y Legislación, Sitial 38. political scientists, should be a source of prayer and call for justice and fair, not to propose viable solutions but to defend tirelessly and effectively inexcusable; it means sacrificing the legitimacy of the ultimate meaning right. The story illustrates and instructs faceless human rights or against the man, but also that it is possible to construct a law that favors; option, is a human law that we claim, which banished the fear of being victims.

\section{Keywords}

Victimology, human rights, humanism

\section{REFLEXIONES PRELIMINARES}

A mediados de este año terminaba de leer la novela Plataforma de Michel Houellebecq, no sólo me había llegado profundamente por las coincidencias con el personaje central: un cuarentón burócrata algo opaco, que logra transformar su vida a partir de la posibilidad de viajar a Oriente con su amante, para pasar por la desgracia de ser víctima de un atentado terrorista. No voy a distraer las ideas que vertebran este breve escrito con aquella obra literaria, sino que voy a referir precisamente lo que inquieta e indigna en el escenario mundial: el miedo a ser víctima.

Hace pocos días, me despierto, con una macabra noticia, heraldos de tragedia: un ataque terrorista cegó la vida a casi dos centenares de personas en Bombay.

La escena infernal, dantesca, se sucedió sin recato una y otra vez en el cinescopio; la repitieron impúdicamente, a discreción: el drama humano vertido en llanto incontenible ya por la pérdida del ser querido o por ser testigo de un impío holocausto; la pantalla no tenía pies ni cabeza, todo ello se asemejaba al Guernica de Picasso; nos acudieron el pasmo, la angustia, el horror, la compasión, la indignación, el miedo, el más profundo y primitivo de los miedos.

Somos mudas víctimas del terrorismo de Estado, del terrorismo de facciones políticas o 
sectas fundamentalistas, del terrorismo de multinacionales, corporaciones criminales, somos víctimas incluso, del terrorismo informativo.

Aún hoy, van y vienen los discursos condenando a los criminales, fluyen amenazas de pesquisas, inquisiciones y ordalías; se alzan los vituperios clamando inveteradas vendettas bíblicas, antediluvianas; mientras, todos los demás tenemos miedo; miedo de las amenazas que otros han hecho en nuestro nombre; miedo, de los resultados de la intervención militar a la que nos opusimos, a voz en cuello, centenares de miles de ciudadanos del mundo, voces que nunca fueron escuchadas.

Hoy, los sordos gobiernos de los estados han dejado de ser humanos, porque lo humano les es ajeno; pues ponderan los intereses geopolíticos, de especulación comercial y financiera, por encima de las garantías de los gobernados.

He aquí, que me aquejan severos cuestionamientos sobre la esencia de mi vocación: la ciencia jurídica; pues no responde ya, al principio que significa el sustrato elemental en el que se edifican sus teorías: la justicia. Sobre todo, porque asumo con claridad las insuficiencias y peligros del decimonónico modelo legalista.

La decadente visión kelseniana de identificar al ordenamiento jurídico con el derecho, y al Estado como monopolizador del acto legislativo y la legítima violencia, es ya categóricamente inadmisible; mientras que la existencia de un derecho natural, desvinculado de la aceptación avasallada frente a la imposición estatal autoritaria y represógena, resulta subversiva; por ello, hoy me declaro abiertamente: insurrecto.

Así pues, la idea de los derechos humanos, pone en crisis al iuspositivismo de estricta observancia, reduccionista; y le han negado relevancia, por el temor de que ese derecho superior, anterior o preexistente, haga resquebrajar el andamiaje del saber jurídico objetivo y puro, derivado del rigor cientificista. ${ }^{1}$

En este sentido, si el derecho pretende mantener su legitimidad y no ser absorbido o neutralizado por economistas, políticos o científicos, debe ser una fuente permanente de invocación y de reclamo por la justicia y lo justo, no para proponer soluciones inviables sino para defenderles incansable, inexcusable y eficazmente; lo contrario, significa sacrificar el sentido último legitimador del derecho. La historia ilustra e instruye sobre derechos sin rostro humano o contrarios al hombre, pero también que es posible construir algún derecho que lo favorezca; la opción, es un humanismo jurídico que nos reivindique, que destierre el miedo de sentirnos víctimas.

\section{ACERCAMIENTO A LA VICTIMOLOGÍA}

Una disciplina innovadora, inscrita en el ámbito de competencia de las ciencias penales, que pretende ser autónoma: es la victimología; en este sentido, se ha entregado a crear una terminología con su semántica propia; a partir de la interacción víctima-criminal como tópico medular.

En esencia, esta disciplina privilegia la posición de la víctima en el proceso penal, al asumir que existe un trauma derivado de la victimización primaria, que suscita sentimientos de frustración y desamparo; toda vez que, los sistemas penales han cifrado su preocupación en descubrir, capturar, juzgar, sentenciar, encarcelar y rehabilitar a los delincuentes, sin prestar demasiada atención a las víctimas de los hechos criminales. $^{2}$

Es indudable que el concepto de la víctima ha evolucionado desde aquél que podía vengarse libremente, hasta el que tenía como límite el

Cfr. VIGO, Rodolfo Luis. De la ley al derecho. Porrúa. México, 2003. p. 23.

2 Cfr. LANDROVE DÍAZ, Gerardo. Víctimas y Sistema Penal Español. Madrid, 1990. pp. 24-26. 
talión, para llegar a la actual identificación del sujeto pasivo del delito.

En una pesquisa etimológica, el término: víctima, apela a dos posibilidades latinas: "vincire", que refiere a los animales sacrificiales destinados a las deidades, o "vincere" que representa el sujeto vencido; estas raíces, romanceadas, pasan al portugués como "vítima", al italiano "vittima", así como al inglés "victim".

No obstante, en su acepción religiosa puede emparentársele con la voz del hebreo: "korban" que implica al individuo que se sacrifica o es inmolado. $^{3}$

La victimología entiende que la víctima, es aquel individuo o grupo social que padece un daño en los bienes jurídicamente protegidos por la normativa penal, por comisión u omisión ajena, o por causa fortuita; inclusive, por accidentes debidos a factores humanos, mecánicos o naturales (como ocurre en los accidentes de trabajo). ${ }^{4}$

Esta definición abarca no sólo al individuo, sino la colectividad, por cuanto son propensos tanto en lo particular como en lo general, a la afectación de los intereses tutelados, por vía de una acción criminal.

Al padecer la persona un daño, se actualiza el supuesto jurídico, de forma tal que, sin el daño, no existe víctima alguna.

La definición aludida, contiene supuestos del daño inquirido por el victimario en vía de acción u omisión (negligencia); o bien, por causa fortuita (por la fuerza de la naturaleza), a quien se le considera damnificado.

Existen diversas propuestas tipológicas de la víctima; una de las primeras tentativas de cla-

3 Cfr. RODRÍGUEZ MANZANERA, Luis. Victimología. Porrúa. México, 2000. p. 28.

4 Cfr. NEUMAN, Elías. Victimología: E1 Rol de la Víctima. Buenos Aires, 1994. pp.4-10. sificación de las víctimas la formula Benjamin Mendelshon; al fin y al cabo, la tipología más difundida y comentada, que se funda en la correlación de culpabilidad entre la víctima y el infractor.

La hipótesis, establece que hay una correlación inversa entre la culpabilidad del agresor y la del ofendido, a mayor culpabilidad de uno menor culpabilidad del otro, lo que trasciende para efectos de aplicación de la pena al infractor.

Los tratados clásicos del derecho penal entienden a la víctima como sujeto pasivo, lo abordan en forma, por demás superflua; pues lo que impera en la dogmática penal, es la teoría del delito.

Incluso, algunos penalistas consideran al sujeto pasivo como un simple elemento del tipo; otros, ni siquiera lo mencionan.

Así pues, la ley margina a la víctima de su ineludible participación en el hecho delictivo y de todo lo relacionado con este; sin embargo, aceptamos cada vez más su participación, pues la contribución de la víctima respecto al crimen, ilumina la situación de culpabilidad y facilita un enjuiciamiento justo.

En atención a lo anterior, no consideramos prudente equiparar al sujeto pasivo del delito con la víctima, ya que este concepto, es más amplio que el primero.

A la sazón, teóricos como Francesco Carnelutti han marcado la diferencia entre perjudicado y ofendido; de tal forma que, perjudicado es la persona cuyo interés ha sido lesionado por el delito; mientras que ofendido, es el perjudicado al que la ley encomienda, a su juicio, la disposición o el goce del bien agredido; de esta forma, una persona es ofendida por el delito, en cuanto se le reconoce el poder jurídico sobre el bien que constituye la materia del acto delictivo.

Así pues, el sujeto pasivo puede ser el individuo, una persona moral, una colectividad o el 
Estado; es decir, un ente capaz de ostentar derechos, o sufrir un ataque a los bienes jurídicos protegidos por la ley. ${ }^{5}$

En este sentido, identificamos con mayor claridad que el sujeto pasivo es el titular del bien jurídicamente protegido, mientras que el ofendido, será aquel que sufra un perjuicio por la comisión del delito y tiene derecho a la reparación del daño.

Por virtud de lo expuesto, las características de la víctima: su personalidad, su conducta y la relación con el victimario, pueden ser trascendentales desde el punto de vista jurídico, pues la configuración del tipo, la existencia o no del delito, la agravación o atenuación de la pena, dependen ya no del autor, sino de las particularidades de la víctima.

Así pues, la víctima puede ejercer una influencia determinante sobre el inicio del proceso penal, sobre su desarrollo y sobre el resultado final del mismo.

La acción penal como derecho subjetivo, nos indica Chiovenda, tiene dos direcciones, "pues se dirige al órgano jurisdiccional a quien se pide la providencia y también al imputado respecto de quien se formula la requisitoria". ${ }^{\circ}$

Es primordial el papel de la víctima al denunciar el delito, pues si no hay queja, la autoridad no puede proceder, a pesar de haberse enterado de los hechos.

Para cerrar con este glosario de términos propios de la victimología, tenemos que victimario, proviene de la voz latina victimarius que, en su acepción original, es el sirviente de los antiguos sacerdotes gentiles, que encendía el fuego, ataba y sujetaba en el acto del sacrificio a las víctimas.
En sentido jurídico, el victimario es aquel que produce el daño, sufrimiento o padecimiento de la víctima; es el sujeto activo del delito de la acción antijurídica.

En el ámbito del derecho procesal penal, se le identifica con el imputado, o sea, la persona a quien se atribuye la comisión de un delito, y que surge desde que se indica a alguien como supuesto autor de un hecho con apariencia delictuosa, desde los momentos iniciales de la investigación hasta la sentencia definitiva, y que lo transforma en condenado, o bien, lo absuelve.

Victimización es la irrupción significativa en la vida o bienes de una persona ejercida por una fuerza externa y que le causa una lesión material o moral seria; así pues, es tanto la consecuencia de una conducta antisocial, como el mecanismo por el cual una persona llega a convertirse en un sujeto pasivo de un hecho punible.

Victimidad, es el conjunto de factores que predisponen a una persona o grupo a ser víctima; victimar, es hacer objeto a otro de una acción victimante, o sea, convertir a alguien en víctima; victimizable, es el sujeto susceptible de ser víctima; victimante, es aquello con capacidad de victimar; victimógeno, lo que puede producir la victimación; victimidad, es el conjunto de factores que predisponen a ser víctima; precipitación victimal, son las contribuciones directas y positivas de la víctima a los hechos.

\section{VICTIMOLOGÍA Y DERECHO VICTIMAL}

La victimología surge a mitad del siglo $\mathrm{XX}$, pues si bien los fundadores de la criminología, presumían la importancia crucial de la relación víctima-delincuente, no fue sino hasta la década de los cuarenta que el término fue invocado por el propio Mendelsohn, uno de los pioneros en la materia. ${ }^{7}$

\footnotetext{
Cfr. MARCHIORI, Hilda. Criminología: la víctima del delito. Porrúa. México, 1998. pp. 1-5.
} 
A partir de entonces, el autor elabora infinidad de trabajos en los que insta a buscar métodos para reducir los elementos perjudiciales de la situación victimal, disminuir la gravedad y la magnitud de las consecuencias, así como prevenir la reincidencia, o sea, la posibilidad de que el individuo llegue a ser víctima de nuevo.

Las obras de Mendelsohn y de Hans Von Hentig, permitieron a la victimología consolidarse, hasta alcanzar el grado de campo de investigación científica.

El objeto de estudio, como ya hemos sugerido previamente, es la descripción del hecho criminal y los factores que lo determinan, por su autor y por la víctima del delito, tanto en su personalidad, como en su posible condición de factor o estímulo del hecho delictivo; sin embargo, es reivindicación tardía, por cuanto los criminólogos han ignorado empecinadamente, la condición de las víctimas del delito. ${ }^{8}$

Así pues, definimos a la victimología como la disciplina que tiene por objeto el estudio de la víctima de un delito, de su personalidad, de sus características biológicas, psicológicas, morales, sociales y culturales, de sus relaciones con el delincuente y del papel que ha desempeñado en la génesis del delito; $y$ aún más allá, analiza el crimen como un problema de dinámica, a fin de construir un sistema de tratamiento y prevención alrededor de la víctima ${ }^{10}$.

Haciendo taxonomía, la criminología proviene del derecho penal; a su vez, la victimología proviene de la criminología, por lo tanto, la victimología está ligada al derecho penal.

Uno de los temas fundamentales del derecho penal que guarda afinidad con la victimología

8 Cfr. SAINZ CANTERO, José A. Lecciones de Derecho Penal. Bosch. Barcelona, 1990. pp. 56-60

9 Cfr. GULOTA, Gianfranco. La Vittima. Giufrre. Varese, 1976. p. 45

10 Cfr. KIRCHHOF, Gers Ferdinand. International debates of victimology. WSV Publishing. 1994. es el sujeto pasivo del delito; y aunque sujeto pasivo y víctima deben ser tratados desde ángulos diferentes, tal y como hemos dicho, las aportaciones de la victimología son definitivas, en tanto prestan mayor atención a este último concepto.

En cuanto al derecho procesal penal, las relaciones con la victimología son estrechas, ya que la participación de la víctima en el proceso, es de cardinal importancia.

De igual forma, la relación con el derecho ejecutivo penal, redunda en avances de los estudios victimológicos realizados en las prisiones y otros lugares de ejecución de la pena.

Ahora bien, en el derecho constitucional, la victimología tiene injerencia en capítulos tan importantes como la violación a las garantías individuales y todas las formas de abuso de poder.

Es así que, la victimología ha matizado el aspecto represivo y unilateral al derecho penal de incidir sólo en el acusado, motivando la protección a la víctima ${ }^{11}$; con ello, se justifica la existencia del derecho victimal.

A partir de lo suscrito, la víctima adquiere tal importancia, pues sus derechos deben ser atendidos por el Estado, previéndose la reparación del daño, por parte del criminal, o bien, del Estado mismo ${ }^{12}$; incluso, extiende su tutela a la prevención del delito y la protección de la víctima; cuestión que, dicho sea de paso, es ya de explorada jurisprudencia.

La propuesta de que el derecho victimal se independice del derecho penal, responde a la insuficiencia de solventar el conflicto de la intervención del Estado como único ofendido, invocando el bien común o la defensa social, marginando a la víctima; pues el acto de autori-

11 Cfr. RODRÍGUEZ MANZANERA. Pp. cit. pp. 4853.

12 Ibid. p. 325 . 
dad, sólo satisface el mero impulso vindicativo de la víctima y no sus consecuencias.

\section{LAPROTECCIÓN CONSTITUCIONAL DE LA VÍCTIMA EN MÉXICO}

Por virtud de senda reforma al párrafo último del artículo 20 de la Constitución Federal, se propone instrumentar mecanismos para que los gobernados encuentren en la norma jurídica tutela y protección respecto de los actos de las autoridades encargadas de la impartición de justicia; asimismo, se reconocen derechos fundamentales para las personas que, por circunstancias involuntarias, han alcanzado la calidad de víctimas o sujetos pasivos de un hecho antisocial o delictivo. A continuación se cita a la letra:

"En todo proceso penal la víctima o el ofendido por algún delito, tendrá derecho a recibir asesoría jurídica, a que se le satisfaga la reparación del daño cuando proceda a coadyuvar con el Ministerio Público, a que se le preste atención médica de urgencia cuando lo requiera $y$, a los demás que señalan las leyes". ${ }^{13}$

No obstante, este precepto constitucional aún carece de una ley reglamentaria en que, las víctimas o sus familiares, se apoyen para exigir las garantías consagradas en sus hipótesis fundamentales; para precisar, estas garantías se enfocan a la materia procesal, es decir, aquellas que tienen las partes cuando acuden a solicitar la prestación jurisdiccional.

Luego entonces, la ley reglamentaria del artículo 20 de la Constitución, deberá regular las siguientes garantías, a saber:

a) Recibir asesoría jurídica: garantía que podría ser otorgada por una institución gubernamental, a manera de defensoría de oficio para víctimas.

13 Diario Oficial de la Federación. 3 de septiembre de 1993. b) Satisfacción de reparación de daño: garantía que debe ser cubierta a la víctima en el momento procesal en que lo solicite.

c) La coadyuvancia con el ministerio público: garantía que podrá ser agotada por los mismos defensores adscritos a la institución de defensoría de oficio para víctimas del delito, que ayudará a integrar el tipo penal y exigir la reparación del daño.

d) Recibir atención médica: garantía fundamental, a fin de atender las lesiones físicas o psicológicas de las víctimas.

Es urgente pues, la creación de una ley federal para la regulación y protección de la figura de la víctima, que permita la concurrencia de los diversos sectores de nuestro país, y la coordinación de esfuerzos de las diversas dependencia federales con las autoridades de las entidades federativas, para su protección.

Para abundar, la regulación constitucional moderna se ha desarrollado respecto al proceso penal, sobre la posición jurídica del inculpado buscando garantizar sus derechos y libertades frente al poder estatal; sin embargo, esa regulación constitucional también debe alcanzar a los demás actores del proceso penal, a fin de darle la integralidad que requiere.

\section{DERECHO VICTIMAL COMPARADO}

El derecho comparado no es una rama especial de la ciencia jurídica, sino que se cifra como un método comparativo, con reglas básicas para alcanzar el objetivo.

Para ello, se debe conocer el derecho extranjero; en relación con la comprensión del ámbito social en que se aplica, se deben examinar sus fuentes, atribuyéndole el mismo valor que lo haría un jurista de ese país; es decir, no tratando de interpretar esas fuentes con la propia formación jurídica; asi mismo, es fundamental el conocimiento de la historia, ideas sociales, políticas y económicas, que tienen aplicación y vigencia en el país que pretende hacerse la comparación. 
No es necesario conocer todo el derecho de un país, para juzgar en forma útil ciertos problemas jurídicos, pues un cierto conocimiento de la estructura del sistema, sus principios generales, sus fuentes, es suficiente para orientar las investigaciones.

El empleo del método comparativo, a pesar de ser un instrumento delicado, es indispensable en el estado actual de la ciencia jurídica; ya que el jurista, para enfrentar los retos que impone el escenario actual, debe conocer los elementos básicos del derecho comparado y atreverse a complementar su formación con el conocimiento de otros sistemas y estructuras jurídicas. ${ }^{14}$

Siguiendo esta propuesta, a fin de robustecer nuestro estudio revisaremos la injerencia de aspectos del derecho victimal en los sistemas jurídicos norteamericano, argentino y español.

Los Estados Unidos de Norteamérica, están conformados por cincuenta estados independientes, cada uno con su propia Constitución; su gobierno se funda en la división de poderes, tanto a nivel estatal como federal; su sistema jurídico, pertenece a la familia anglosajona del common law.

Los estados, tienen autoridad sobre la mayor parte de los aspectos de la vida pública, con excepción de los conferidos expresamente al gobierno federal.

El sistema judicial es de doble jerarquía jurisdiccional, ya que la competencia de las jurisdicciones federales depende de la naturaleza del litigio y la naturaleza de las partes.

La mayor actividad forense se advierte en los tribunales estatales, ya que sólo el $5 \%$ de las causas son ventiladas ante la Corte Federal, en la que se plantean cuestiones de derecho que provocan debate nacional.

14 Cfr. VALLARTA PLATA, José Guillermo. Introducción al Estudio del Derecho Comparado del Derecho Constitucional. Porrúa. México, 1998. pp. 1-5.
Las veintiséis enmiendas a la Constitución Federal representan los derechos de los ciudadanos ante el gobierno; las diez primeras se consideran el Bill of Rights (catálogo de garantías).

Los esfuerzos en materia de atención a víctimas entienden: el establecimiento de programas de restitución para el ofendido, compensación del Estado y asistencia gubernamental, así como garantías para asegurar el tratamiento de las víctimas en el proceso judicial.

Los estados de Arizona, California, Florida, Georgia, Michigan, Texas y Washington, en sus respectivas constituciones, prevén derechos como la necesidad financiera de la víctima, en la figura de la compensación estatal.

El Derecho de la víctima, de estar presente en todo el juicio se llama desideratum, y se concede de diferentes maneras; por ejemplo, en Florida la víctima puede estar presente hasta donde la extensión de derechos del defendido no sean infringidos; en Texas, puede estar presente, siempre y cuando su testimonio no afecte otro testimonio.

Algunos conflictos constitucionales se generan por los diferentes objetivos entre las víctimas y las enmiendas constitucionales; aunque algunos estados ya han adoptado tales modificaciones no pueden llevarse acabo, pues no pueden encausarse y justificarse en la unión de objetivos. ${ }^{15}$

Los bienes jurídicos tutelados y los límites a la potestad punitiva del Estado que dan base al principio de la necesidad de la pena como última ratio del ordenamiento jurídico, y que se encuentran implícitos en el estado de derecho, han sido objeto de preocupación de los juristas del sistema continental.

En época reciente se ha llegado a la categórica trascendencia de la afectación de la potestad, en la creación del delito.

15 LAMBORN, Leroy. "La Constitucionalización de las víctimas en los Estados Unidos". Curso Internacional de Criminología. ULSA. México, 1995. 
En los Estados Unidos, existe una larga tradición jurisprudencial acerca de la invalidez de las leyes penales que castigan comportamientos que suponen "sustancial perjuicio para el público", expresión de noción de bien jurídico tutelado, derivación del principio del debido proceso de las enmiendas V y XVI de su norma constitucional. ${ }^{16}$

En Argentina, coexisten dos órdenes normativos constitucionales: el nacional y el provincial.

A partir la reforma de 1994, el sistema jurídico argentino ha incorporado importantes hipótesis que, en relación a la víctima, aquí comentamos:

a) Debido proceso. La Corte Suprema de Justicia de la Nación sostiene que todo aquel a quien la ley le reconoce personería para actuar en juicio en defensa de sus derechos, está amparado por la garantía del debido proceso legal, consagrada en el Artículo 18 de la Constitución Nacional, sea que actúa como acusador o acusado, demandante o demandado.

b) Igualdad ante la ley. Tocante a la víctima resulta contradictorio que el Estado se apropie del conflicto y coloque en una especie de capacidad disminuida a la víctima, pues entonces se acentúa el proceso de victimización y, por lo tanto, de desigualdad en su posición.

c) Derechos no enumerados. El Artículo 33 de la Constitución Nacional Argentina, reconoce derechos no enumerados, los cuales nacen del principio de la soberanía del pueblo y de la forma republicana de gobierno; entre ellos, podemos entender incluidos, los de la víctima.

El contraste entre delincuente y víctima está claramente atenuado en la legislación argentina, ya que se incrimina, cada vez con mayor

16 Cfr. HENDLER, Edmundo. Derecho Penal en Estados Unidos de América. Instituto Nacional de Ciencias Penales (INACIPE). México. pp. 125-135. frecuencia, delitos con el innovador concepto de víctimas difusas.

En beneficio de la víctima, el derecho penal argentino, ha ido sustituyendo la causación del daño, por la idea de la puesta en peligro.

En el sistema del Código Penal argentino, se advierte una notoria referencia a la persona individual, ello como una especie de contrafigura del autor del delito.

La acción penal procesal se limita en su contenido, por las figuras jurídicas delictivas tipificadas.

La acción penal pública constituye la regla en el derecho argentino; no obstante, las acciones privadas nacen de los delitos de calumnias, violación de secretos, concurrencia desleal.

El artículo 79 del código vigente, menciona que desde el inicio del proceso penal y hasta su finalización, el Estado Nacional garantizará a las víctimas de un delito el pleno respeto a los derechos de recibir un trato digno y respetuoso, a la protección de su integridad física y moral y a que sea informado de los actos procesales.

El código, impone al órgano jurisdiccional competente la obligación de hacerle conocer a la víctima que posee los derechos enunciados en sus artículos.

La consagración expresa de que, a la víctima le asisten derechos, con relación al procedimiento que desarrolla el Estado, debe favorecer la creación de un servicio público de asesoramiento y asistencia a las víctimas y testigos; asimismo, la regulación, también explícita, del ejercicio de la acción civil en la sede penal, determinan un sólido avance. ${ }^{17}$

17 Cfr. BERMÚDEZ, Víctor Hugo. La víctima en el Proceso Penal, su régimen en Argentina. Depalma. Buenos Aires, 1995. pp. 20-47. 
Al parecer, el sistema jurídico español no presta demasiada atención a las víctimas y no existe impulso suficiente para abordar la construcción de programas asistenciales e indemnizatorios semejantes a los ya existentes en otros países.

La legislación, no supone la concesión formal de derechos o acciones para satisfacer las necesidades sentidas por una persona victimizada, si al mismo tiempo no se establecen las condiciones materiales imprescindibles para que esta satisfacción tenga efectivamente lugar.

Esta desprotección de las víctimas a nivel reparatorio no significa, sin embargo, que el legislador haya ignorado la relevancia del papel jugado por el protagonista del drama criminal.

El Código Penal español presta poca atención al comportamiento y situación de las personas que, al ser lesionados en sus derechos, quedan promovidas a la condición de víctimas, así en la fase previa a la comisión del hecho delictivo y durante su ejecución o con posterioridad a la consumación; de igual forma, respecto del papel desempeñado por la víctima en la génesis del hecho criminal, en la preparación y ejecución del delito, y también en los momentos posteriores a la consumación; así pues, el delito se persigue, enjuicia y sanciona con independencia de la intervención de la víctima en su aparición, y prescindiendo de la actitud de la misma respecto de la pena y demás consecuencias jurídicas de la infracción.

Este principio general ofrece, en cualquier caso, significativas excepciones, pues en la fase postdelictiva, la víctima adquiere un cierto protagonismo, ya que se le reserva la iniciativa sobre la puesta en marcha del procedimiento y en algunos casos, puede perdonar al victimario; finalmente, sus intereses se tienen en cuenta, en función de la posible responsabilidad civil.

La problemática del sistema español, se concreta en el vacío legislativo respecto de la víctima, ya que no disponen de una normativa en orden a la indemnización por el Estado a favor de las víctimas desamparadas de determinadas infracciones criminales. ${ }^{18}$

\section{EL DERECHO VICTIMAL EN EL ORDEN INTERNACIONAL}

La Asamblea General de la Organización de las Naciones Unidas, el 29 de noviembre de 1985, adoptó en su resolución 40/34, la Declaración sobre los principios fundamentales de justicia para las víctimas de delitos y del abuso de poder, y por la importancia que reviste para tratar el tópico, nos permitimos abordarlo con la precisión de sus diversos componentes temáticos.

El documento en cuestión, entiende por víctimas, a las personas que, individual o colectivamente, hayan sufrido daños, inclusive lesiones físicas o mentales, sufrimiento emocional, pérdida financiera o menoscabo sustancial de los derechos fundamentales, como consecuencia de acciones $u$ omisiones que violen la legislación penal vigente en los estados miembros, incluida la que proscribe el abuso de poder.

Se considera víctima a una persona, independientemente de que se identifique, aprehenda, enjuicie o condene al perpetrador e independientemente de la relación familiar entre el perpetrador y la víctima.

En la expresión, se incluye además, en su caso, a los familiares o personas a cargo, que tengan relación inmediata con la víctima directa y a las personas que hayan sufrido daños al intervenir para asistir a la víctima en peligro o para prevenir la victimización.

Las disposiciones de dicha Declaración son aplicables a todas las personas sin distinción alguna, ya sea de raza, color, sexo, edad, idioma, religión, nacionalidad, opinión política o de otra índole, creencias o prácticas culturales, situación económica, de nacimiento o situación familiar, origen étnico o social, o impedimento físico.

18 Cfr. LANDROVE DÍAZ. op. cit. pp. 88-108. 
Postula, que las víctimas sean tratadas con compasión y respeto por su dignidad; que tengan derecho de acceso a los mecanismos de la justicia y a una pronta reparación del daño que hayan sufrido, según lo dispuesto en la legislación nacional.

Pretende se establezcan y refuercen, mecanismos judiciales y administrativos que permitan a las víctimas obtener reparación mediante procedimientos oficiales $\mathrm{u}$ oficiosos que sean expeditos, justos, poco costosos y accesibles; informándose a las víctimas de sus derechos para obtener reparación mediante esos mecanismos.

Para ello, se deberá facilitar la adecuación de los procedimientos judiciales y administrativos a las necesidades de las víctimas:

a) Informando a las víctimas de su papel y del alcance, el desarrollo cronológico y la marcha de las actuaciones, así como de la decisión de sus causas, especialmente cuando se trate de delitos graves y cuando hayan solicitado esa información;

b) Permitiendo que las opiniones y preocupaciones de las víctimas sean presentadas y examinadas en etapas apropiadas de las actuaciones siempre que estén en juego sus intereses, sin perjuicio del acusado y de acuerdo con el sistema nacional de justicia penal correspondiente;

c) Prestando asistencia apropiada a las víctimas durante todo el proceso judicial;

d) Adoptando medidas para minimizar las molestias causadas a las víctimas, proteger su intimidad, en caso necesario, y garantizar su seguridad, así como la de sus familiares y la de los testigos en su favor, contra todo acto de intimidación y represalia; y,

e) Evitando demoras innecesarias en la resolución de las causas y en la ejecución de los mandamientos o decretos que concedan indemnizaciones a las víctimas.

Propende por que se utilicen, cuando proceda, mecanismos oficiosos para la solución de con- troversias, incluidos la mediación, el arbitraje y las prácticas de justicia consuetudinaria o autóctonas, a fin de facilitar la conciliación y la reparación en favor de las víctimas.

Advierte que los delincuentes o los terceros responsables de su conducta deben resarcir equitativamente, cuando proceda, a las víctimas, sus familiares o las personas a su cargo. Ese resarcimiento, comprenderá la devolución de los bienes o el pago por los daños o pérdidas sufridos, el reembolso de los gastos realizados como consecuencia de la victimización, la prestación de servicios y la restitución de derechos.

Para ello, los gobiernos deben revisar sus prácticas, reglamentaciones y leyes, de modo que, se considere el resarcimiento como una sentencia posible en los casos penales, además de otras sanciones penales.

En los casos en que se causen daños considerables al medio ambiente, el resarcimiento que se exija debe comprender, en la medida de lo posible, la rehabilitación del medio ambiente, la reconstrucción de la infraestructura, la reposición de las instalaciones comunitarias y el reembolso de los gastos de reubicación, cuando esos daños causen la disgregación de una comunidad.

Considera también que, cuando funcionarios públicos u otros agentes que actúen a título oficial o cuasioficial hayan violado la legislación penal nacional, las víctimas serán resarcidas por el Estado cuyos funcionarios o agentes hayan sido responsables de los daños causados. En los casos en que ya no exista el gobierno bajo cuya autoridad se produjo la acción u omisión victimizadora, el Estado o gobierno sucesor deberá proveer al resarcimiento de las víctimas.

Así, cuando no sea suficiente la indemnización procedente del delincuente o de otras fuentes, los Estados procurarán indemnizar financieramente:

a) A las víctimas de delitos que hayan sufrido importantes lesiones corporales o menos- 
cabo de su salud física o mental como consecuencia de delitos graves; $y$,

b) A la familia, en particular a las personas a cargo de las víctimas que hayan muerto o hayan quedado física o mentalmente incapacitadas como consecuencia de la victimización.

Pretende se fomente el establecimiento, el reforzamiento y la ampliación de fondos nacionales para indemnizar a las víctimas. Cuando proceda, también podrán establecerse otros fondos con ese propósito, incluidos los casos en los que el Estado de nacionalidad de la víctima no esté en condiciones de indemnizarla por el daño sufrido.

Señala que las víctimas deben recibir la asistencia material, médica, psicológica y social que sea necesaria, por conducto de los medios gubernamentales, voluntarios, comunitarios y autóctonos.

Para ello, se informará a las víctimas de la disponibilidad de servicios sanitarios y sociales y demás asistencia pertinente, y se facilitará su acceso a ellos, proporcionando al personal de policía, de justicia, de salud, de servicios sociales y demás personal interesado, capacitación que lo haga receptivo a las necesidades de las víctimas y directrices que garanticen una ayuda apropiada y rápida, prestando primordial atención a las que tengan necesidades especiales por la índole de los daños.

Refiere un aspecto medular para el presente estudio, al señalar que entiende por víctimas de abuso de poder, a las personas que, individual o colectivamente, hayan sufrido daños, inclusive lesiones físicas o mentales, sufrimiento emocional, pérdida financiera o menoscabo sustancial de sus derechos fundamentales, como consecuencia de acciones $u$ omisiones que no lleguen a constituir violaciones del derecho penal nacional, pero violen normas internacionalmente reconocidas relativas a los derechos humanos.
Para ello, los Estados deben considerar la posibilidad de incorporar a la legislación nacional normas que proscriban los abusos de poder y proporcionen remedios a las víctimas de esos abusos. En particular, esos remedios incluirán el resarcimiento y la indemnización, así como la asistencia y el apoyo materiales, médicos, psicológicos y sociales necesarios.

Insta a que los Estados consideren la posibilidad de negociar tratados internacionales multilaterales relativos a las víctimas de abuso de poder, que revisen periódicamente la legislación y la práctica vigentes para asegurar su adaptación a las circunstancias cambiantes, para promulgar y aplicar, en su caso, leyes por las cuales se prohíban los actos que constituyan graves abusos de poder político o económico y se fomenten medidas y mecanismos para prevenir esos actos, y establecerán derechos y cursos adecuados para las víctimas de tales actos, facilitándoles su ejercicio.

\section{LA VÍCTIMA Y LOS DERECHOS HUMANOS}

En 1942, Europa era invadida por el ejército nazi, que intentaba imponer un "nuevo orden"; y no sólo los judíos fueron víctimas de sendas abominaciones y abusos, de crímenes de lesa humanidad.

La innenarrable crueldad desplegada en campos de concentración y exterminio, pervive en la memoria colectiva.

Al finalizar la Segunda Guerra Mundial, veinticuatro miembros de la cúpula nazi fueron 1levados a juicio, acusados de crímenes de guerra, doce de los cuales fueron sentenciados a muerte, siete condenados a penas de reclusión, tres fueron absueltos y uno resultó desglosado.

Hoy, en el Oriente próximo, las peores atrocidades que acontecen, se deben por un amplio margen a las potencias colonialistas que aposentaron sus intereses económicos en la zona, dejando un reguero de sangre y destrucción en 
territorios palestinos bajo la ocupación militar de Israel, aún no se señalan culpables.

El sistema del apartheid, entiende la total o parcial exclusión de una categoría o grupo de personas, les segrega de la participación en las decisiones sociales, económicas y políticas trascendentales; de hecho, les niega diversos derechos, bajo argumentos, ya religiosos o de seguridad nacional.

A pesar de que el modelo de discriminación social sudafricano del apartheid, está oficialmente proscrito, podemos encontrarlos en diversas partes del mundo, ya enmascarados o con algunas variantes, no obstante todas con el mismo componente: el odio racial.

Sin pena y con gran preocupación, hay que señalar las condiciones de marginación, explotación, ignorancia, pobreza, y ausencia de servicios públicos a que han sido condenadas una gran cantidad de comunidades indígenas, a lo largo y ancho de nuestro país; los indígenas, utilizados sólo para el discurso político hueco, han sido sometidos al frío olvido de la estadística, al desamparo y al mercadeo del folclor; eso, por supuesto que es discriminación.

Aún hoy para muchas mujeres, acceder libremente a actividades laborales y recibir beneficios sociales, resulta imposible; y en ciertos países integristas, ni si quiera les son reconocidos los más esenciales derechos fundamentales.

Cuando en el extenso territorio del mundo subdesarrollado encuentran las mujeres trabajo, no es siempre en las mejores condiciones; muchas de ellas, son sometidas a hostilidades y trato inclemente, alejado de todo principio universal de derecho laboral.

Queda aún como vergonzante caso abierto, el vejamen y asesinato de un indignante número mujeres en Ciudad Juárez.

En los países desarrollados, principalmente en los Estados Unidos, la condición a la que son sometidos los trabajadores migrantes indocumentados es cruel e inhumana; no sólo se les persigue como criminales, sino que se les niegan servicios humanitarios.

A pesar del abismo siempre creciente que separa a los ricos y a los pobres y del que tanto habla la ONU, y no obstante la muy discutida extinción de la clase media en Occidente, el ataque contra el empleo y el nivel de ingreso, no es quizá, el delito corporativo más grave al que nos enfrentamos como ciudadanos del mundo, y que en teoría no es irreversible.

A largo plazo, peores serán los crímenes que las grandes corporaciones empresariales, en contumacia con gobiernos que les son serviles, cometen contra el medio ambiente, contra las reservas alimentarias, contra los pueblos y las culturas indígenas, y contra los derechos humanos. ${ }^{19}$

Todas estas, son asignaturas pendientes y urgentes de resolver: la intolerancia, la descarnada violencia, la inseguridad, la injusticia, el terrorismo, la violación a los derechos humanos; desentenderse de ellas, implica dolosa complicidad; el Derecho tiene una encomienda milenaria, hoy debemos romper nuestra visión atávica, repensarlo, reconstruirlo, es deber y vocación reivindicar a las víctimas y edificar un refugio donde convivan el mundo real y la justicia.

\section{BIBLIOGRAFÍA}

BERMÚDEZ, Víctor Hugo. La víctima en el proceso Penal en América del Sur: su régimen en Argentina. Depalma. Buenos Aires, 1995.

GULOTTA, Gianfranco. La Vittima. Giuffre. Várese, 1976.

HENDLER, Edmundo. Derecho Penal en Estados Unidos de América. INACIPE. México, 1992.

19 Cfr. KLEIN, Naomi. No logo. El poder de las marcas. Paidós. Barcelona, 2001, pp. 316-317. 
KIRCHHOF, Gerd Ferdinand. International Debates of Victimology. WSV Publishing, 1994.

KLEIN, Naomi. No logo. El poder de las marcas. Paidós. Barcelona, 2001.

LANDROVE DÍAZ, Gerardo. Victimas y Sistema Penal Español. Tirant lo Blanch. Valencia, 1990.

lencia, 1990.

Victimología. Tirant lo Blanch. Va-

MARCHIORI, Hilda. Criminología: la víctima del delito. Porrúa. México, 1998.

México, 1996.

El Estudio del Delincuente. Porrúa. México, 1996.

Personalidad del delincuente. Porrúa.

MELIA CANCIO, Manuel. Conducta de la víctima e imputación objetiva en Derecho Penal. Bosch. Madrid, 1998.
NEUMAN Elías, Victimología: El Rol de la víctima. Buenos Aires, 1994.

RODRÍGUEZ MANZANERA, Luis. Criminología. Porrúa. México,1998.

Victimología: Estudio de la víctima. Porrúa. México, 2000.

RUBIANES, Carlos. Derecho procesal Penal. Desalma. Buenos Aires, 1985.

SAINZ CANTERO, José Antonio. Lecciones de Derecho Penal. Bosch. Barcelona, 1990.

VALLARTA PLATA, José Guillermo. Introducción al estudio del derecho comparado del derecho constitucional. Porrúa. México, 1998.

VIGO, Rodolfo Luis. De la ley al derecho. Porrúa. México, 2003. p. 23

WELZEL, Hans. Derecho Penal Alemán. Editorial Jurídica. Santiago de Chile, 1996. 